\title{
Evaluation of Non-Isothermal Kinetic Parameters for Pyrolysis of Teak Wood using Model-Fitting Techniques
}

\author{
Adekunle Adeleke ${ }^{1, *}$, Peter Ikubanni ${ }^{1}$, Jamiu Odusote ${ }^{2}$, Thomas Orhadahwe ${ }^{3}$, \\ Olumuyiwa Lasode ${ }^{4}$, Samuel Adegoke ${ }^{5}$ and Olanrewaju Adesina ${ }^{1}$ \\ ${ }^{1}$ Mechanical Engineering Department, Landmark University, PMB 1001, Omu-Aran, Nigeria \\ ${ }^{2}$ Materials and Metallurgical Engineering Department, University of Ilorin, PMB 1515, Ilorin, Nigeria \\ ${ }^{3}$ Mechanical Engineering Department, University of Ibadan, Ibadan, Nigeria \\ ${ }^{4}$ Mechanical Engineering Department, University of Ilorin, PMB 1515, Ilorin, Nigeria \\ ${ }^{5}$ Petroleum Engineering Department, University of Ibadan, Ibadan, Nigeria
}

('Corresponding author’s e-mail: adeleke.kunle@ymail.com)

Received: 18 July 2020, Revised: 5 May 2021, Accepted: 18 June 2021

\begin{abstract}
Teak wood is one of the prominently used raw material in the construction industry, thus contributing extremely to the biomass waste available in Nigeria. These wastes are usually used for energy generation that requires upgrade into better fuel before application. Hence, the present study evaluates the non-isothermal kinetic parameters for pyrolysis of teak wood using model-fitting techniques. Teak wood dust was subjected to proximate, ultimate and calorific value analyses based on different ASTM standards. The thermal degradation and decomposition behaviour of the teak wood dust was examined using a thermogravimetric analyzer. Pulverized teak $(6.5 \mathrm{mg})$ was heated from 30 to 800 ${ }^{\circ} \mathrm{C}$ at varying heating rates $\left(5,10\right.$ and $\left.15{ }^{\circ} \mathrm{C}\right)$ in an environment where $100 \mathrm{~mL} / \mathrm{min}$ of nitrogen gas was charged in continuously to maintain an inert condition. Avrami-Erofeev, Ginstling-Broushtein (GB) and Mampel models were used to evaluate the kinetic parameters of the pyrolysis of teak wood dust. The teak wood dust contained $7.25 \%$ moisture, $79.26 \%$ volatile matter (VM), $1.74 \%$ ash and $11.75 \%$ fixed carbon. The calorific value of the wood dust was $18.72 \mathrm{MJ} / \mathrm{kg}$. The results of the thermogravimetric analyses depicted that heating rate has no effect on weight loss during the reactive drying zone. However, as the thermal treatment progressed into the active pyrolysis and passive pyrolysis zones, the weight loss decreased with increase in heating rate. The devolatilization parameters also increased with heating rates except for the maximum conversion. The results of the kinetic parameters evaluation revealed that the GB model was best fit to evaluate the kinetic parameters of teak in the active pyrolysis zone while GB and Mampel models were considered most appropriate for the evaluation of the kinetic parameters in the passive pyrolysis zone. Model-fitting method has the capacity to capture a wide range of fractional conversion at a glance.
\end{abstract}

Keywords: Model-fitting techniques, Teak wood dust, Thermogravimetry, Frequency factor, Activation energy

\section{Introduction}

Climate change and its adverse effect on man and the environment are as a result of overdependence on the use of fossil fuel as energy source for human activities. This has necessitated numerous researches into the use of alternative energy sources such as biomass. These biomasses are readily available at low cost and are environmental friendly [1-4]. This energy source has been classified as a renewable energy because of its potential for sustainability and environmental friendliness [5,6]. The level of $\mathrm{SO}_{\mathrm{x}}$ and $\mathrm{CO}_{2}$ emissions can be reduced by blending biomass with fossil fuel such as coal, but the heating value of the fuel are often lowered due to rich oxygen and hydrogen content of the biomass [7,8]. This is however compensated for by the low activation energy of the blend due to the presence of oxygen in the biomass which aids combustion. Biomass can be converted into useful products by thermochemical processing through pyrolysis. During pyrolysis, biomass is changed to gases, liquid and char [9]. Pyrolysis is the thermal degradation of biomass which occurs in the absence of oxygen and other gasses [10]. The pyrolysis kinetics of biomass can be examined through time-based thermal dissociation [11]. Non- 
isothermal kinetic evaluation is a suitable thermal analysis method that has been deployed in the study of pyrolysis kinetics of woody biomass [12].

Pradhan et al. [13] explained various models for the pyrolysis of biomass. Isoconversional model is the most commonly used model for explaining the kinetic behaviour of lumped biomass. It takes into cognizance kinetic parameters like frequency factor and activation energies during pyrolysis [9]. These factors can be investigated using model-fitting models [14]. Thermogravimetric analysis (TGA) has been adopted by many researchers as a reliable method for studying thermal behaviour of biomass $[1,15,16]$. TGA deploys the use of non-isothermal methods which requires that change in weight be measured as a function of temperature [17]. Model fitting methods assume that the reaction mechanism and specific rate constant fit suitably with the results obtained from the TGA [12]. The mineral composition of feedstock affects its torrefaction behaviour and heating value of biomass [17]. Also, the architecture and specific gravity of different tree species vary [18], hence the need to examine their non-isothermal kinetic parameters prior to use. Teak wood dust is considered the most important deciduous plant in tropic region, due to the ease of conversion into timber. The broad leaves tree is native to many tropical countries like Brazil, Thailand, India and Nigeria [18,19]. Due to its high usefulness, a lot of wastes are generated from the plant which can be converted into useful forms through thermochemical processes $[14,20]$.

There are numerous studies on non-isothermal kinetic parameters evaluation for various biomass and solid fuels $[11,21,22]$. These works laid a solid foundation to obtain the kinetic parameters of biomass especially teak wood with the aim of producing biofuel from it through pyrolysis process. Thus, the objective of the present study is to obtain Arrhenius parameters in terms of activation energy and preexponential factor for the pyrolysis of teak wood while comparing 4 different model-fitting techniques

\section{Materials and methods}

\section{Sample preparation}

The biomass used in this study was teak wood. The wood was obtained from Benin, Nigeria. It was transformed into fines below $6.35 \mathrm{~mm}$ using a saw wood cutting machine (Model No: CS33EB). The wood chips and fines were sun-dried for 5 days (6 h/day). A Laboratory Mill (Thomas Wiley, Model 4) was then use to further pulverize the wood chips and screened to $<0.5 \mathrm{~mm}$.

\section{Sample characterization and thermogravimetric experiment}

The ultimate, proximate and calorific analyses (higher heating value (HHV)) of the teak wood dust were determined based on different ASTM and BS standards. Moisture content (MC) was determined based on ASTM E871-81 standard while the VM content was obtained using BS EN 15148 standard. The ash content (AC) was determined in accordance with the ASTM E1755-01 standard. Fixed carbon of the sample was then determined by difference $(100-(\mathrm{MC}+\mathrm{AC}+\mathrm{VM}))$. The ultimate analyses $(\mathrm{CHN})$ was obtained in a LECO-CHN 628 analyzer using ASTM D5373 while Sulphur content was obtained based on ASTM D4239-11 techniques. The oxygen content was evaluated by difference $(100-(\mathrm{C}+\mathrm{H}+\mathrm{N}+\mathrm{S}$ + AC)). The calorific values of the teak wood dust was gotten from a Par 6200 oxygen bomb calorimeter following ASTM D5865-04 method. A thermogravimetric analyser (Model No: STA7300) was used for the observation of the thermal degradation and decomposition behaviour of teak wood dust, where the approximate test sample loaded into the crucible for analysis was $6.5 \mathrm{mg}$. An inert environment with 100 $\mathrm{mL} / \mathrm{min}$ nitrogen gas continuous flow was used for the experiment. The samples were heated from 30 to $800{ }^{\circ} \mathrm{C}$ at different heating rates of 5,10 , and $15^{\circ} \mathrm{C} / \mathrm{min}$.

\section{Evaluation of kinetic parameters using model-fitting techniques}

The reaction scheme for thermal decomposition of teak wood dust is expressed by Eq. (1) [23]:

$\alpha A_{\text {solid }} \rightarrow b B_{\text {solid }}+c C_{\text {gas }}$

The mass loss during this process of decomposition follows the solid-state reaction rate law as presented in Eq. (2) [23]. The heating rate was incorporated into it since the thermogravimetry was done with a constant heating rate under non-isothermal condition thereby the rate reaction was described as a function of temperature as given in Eq. (3) [23]:

$\frac{d \alpha}{d t}=A \exp ^{-E_{a} / R T} \mathrm{f}(\alpha)$

$d \alpha / d T=d \alpha / d t \times d t / d T$ 
where $d \alpha / d T$ is the non-isothermal reaction rate, $\alpha$ is the conversion fraction, $d T / d t=\beta$ is the heating rate, $E_{a}$ is the activation energy, $\mathrm{A}$ is the frequency factor/pre-exponential factor, $\mathrm{T}$ is the temperature in $\mathrm{K}, f(\alpha)$ is the reaction model and $\mathrm{R}$ is the gas constant. Eq. (4) which is the differential form of the nonisothermal rate law, was obtained by substituting Eq. (2) into Eq. (3).

$\frac{d \alpha}{d T}=A / \beta \exp ^{-E_{a} / R T} \mathrm{f}(\alpha)$

By separating variables and integrating Eq. (4), the integral form of the non-isothermal rate law was obtained and it is presented as Eq. (5):

$\mathrm{g}(\alpha)=\frac{A}{\beta} \int_{0}^{T} e^{-E_{a} / R T} d t$

where $\mathrm{g}(\alpha)$ is the integrated form of the conversion dependence which is without a specific analytical solution. Let $x$ replace $\frac{-E_{a}}{R T}$, Eq. (5) becomes Eq. (6) by transforming the limits:

$\mathrm{g}(\alpha)=\frac{A E_{a}}{\beta R T} \int_{x}^{\infty} \frac{e^{-x}}{x^{2}} d x$

Replacing the integral part with $p(x)$ which is a standard one, we have Eq. (7):

$\mathrm{g}(\alpha)=\frac{A E_{a}}{\beta R T} p(x)$

The Coats and Redfern [24] method is a prevailing approximation proposed for solving $p(x)$, which does not have an exact solution. The solution proffer by Coats and Redfern [24] was adopted for this study and it leads to Eq. (8):

$\ln \left\lfloor\frac{g(\alpha)}{T^{2}}\right\rfloor=\ln \left\lfloor\frac{A R}{\beta E_{a}}\left(1-\frac{2 R \bar{T}}{E_{a}}\right)\right\rfloor-\frac{E_{a}}{R T}$

Generally, the term $2 R \bar{T} / E_{a}$ is much less than unity for thermal decomposition of polymeric materials. Therefore, the plots of $\ln \left\lfloor\frac{\mathrm{g}(\alpha)}{T^{2}}\right\rfloor$ against $\frac{1}{T}$ for different models gives straight lines with $\frac{-E_{a}}{R}$ as slopes and $\ln \left\lfloor\frac{A R}{\beta E_{a}}\right\rfloor$ as intercepts from which A was determined for APZ and PPZ. For thermogravimetric data, $\alpha$ was calculated via Eq. (9):

$\alpha=\frac{m_{o}-m_{t}}{m_{o}-m_{f}}$

where $m_{o}$ and $m_{f}$ are the initial and final mass of the reactant respectively, and $m_{t}$ is the mass at a temperature.

The 4 models adopted for $\mathrm{g}(\alpha)$ are given in Eqs. (10) (Avrami-Erofeev), (11) (Ginstling-Broushtein model (GB), (12) (Mampel) and (13) (SSS):

$$
\begin{aligned}
& \mathrm{g}(\alpha)=[-\ln (1-\alpha)]^{1 / 2} \\
& \mathrm{~g}(\alpha)=(1-2 \alpha / 3)-(1-\alpha)^{2 / 3} \\
& \mathrm{~g}(\alpha)=-\ln (1-\alpha) \\
& \mathrm{g}(\alpha)=1-(1-\alpha)^{1 / 3}
\end{aligned}
$$

\section{Results and discussion}

Characterization, decomposition changes and degradation mechanism of the teak wood dust

The results of the proximate, ultimate and calorific value analyses of the teak wood dust in the present study compared with results of previous research works are presented in Table 1. It is revealed that the moisture content, VM and ash content are 7.25, 79.26 and $1.74 \%$, respectively. The fixed carbon content of teak wood dust is $11.75 \%$ which is slightly higher than of melina as reported by Adeleke et al. [19]. The ultimate analysis showed that the woody biomass is composed of carbon (47.84\%), hydrogen $(6.09 \%)$, nitrogen $(0.39 \%)$, oxygen $(45.42 \%)$ and sulphur $(0.26 \%)$ with a calorific value of 18.72 $\mathrm{MJ} / \mathrm{kg}$. The ranges of value obtained for these properties are common for tropical woody biomass [19,26]. Figure 1 shows the thermogravimetric curves for the teak wood dust at different heating rates. The curves in Figure 1 shows 3 distinct zones; a moisture evolution and drying zone (A), active pyrolysis zone (B) and passive pyrolysis zone (C) which is line with the findings of Kamble et al. [27]. The 3 zones were 
identified by Kothandaraman and Somasundaram [11] as cellulose, hemicellulose and lignin degradation zones, respectively. In zone A $\left(50\right.$ to $\left.200{ }^{\circ} \mathrm{C}\right)$, as temperature rises, the moisture content of the wood was lost due to evaporation. The temperature at which this occurs and weight loss are independent of the heating rate. However, as the heating proceeds into zones $\mathrm{B}\left(200\right.$ to $\left.400{ }^{\circ} \mathrm{C}\right)$ and $\mathrm{C}\left(>400{ }^{\circ} \mathrm{C}\right)$, a variation in the weight loss due to the various heating rates was observed. The sample exposed to $5^{\circ} \mathrm{C} / \mathrm{min}$ heating rates experienced the most weight loss while the sample with $15{ }^{\circ} \mathrm{C} / \mathrm{min}$ heating rate showed the least weight loss in both zones. This shows that weight loss decreases with increase in heating rate. According to Guida et al. [15], heating rate plays an important role in the pyrolysis of biomass as maximum decomposition rate increases with higher heating rates. Figure 2 represents the DTG for the teak wood dust at the 3 heating rates. The maximum DTG peak temperature for the teak wood dust ranges from 321 to $341{ }^{\circ} \mathrm{C}$ at the different heating rates (Table 2). This was linked to cellulose degradation [4,25]. The lignin content of teak wood dust degraded around $341-550{ }^{\circ} \mathrm{C}$. Figure 2 revealed that above $550{ }^{\circ} \mathrm{C}$, there was a continuous mild weight loss, which was suggested to be fractional thermal cracking of some chemical bonds possibly formed at the initial devolatilization $[25,26]$. The temperature at which devolatilization begins $\left(\mathrm{T}_{\text {onset }}\right.$ ) was slightly affected by change in heating rates as shown in Table 2 . This was mirrored by the temperature that showed the termination of degradation of cellulose $\left(T_{\text {offset }}\right)$. $T_{\text {burnout }}$ that represent the temperature at which weight loss of the sample remain constant/relatively unchanged increased with heating rates. The maximum cellulose decomposition $\left(\mathrm{DTG}_{\mathrm{peak}}\right)$ increased from 0.3824 to $0.9210 \mathrm{mg} / \mathrm{min}$. The maximum conversion $\left(\propto_{\max }\right)$ reduced from $50.21 \%$ at $5{ }^{\circ} \mathrm{C} / \mathrm{min}$ to $47.46 \%$ at 15 ${ }^{\circ} \mathrm{C} / \mathrm{min}$. The result trend was similar to what was reported by Adeleke et al. [25] for decomposition parameters of melina wood dust. The implication is that lower heating rates results in higher weight loss that was encouraged by mass diffusion mechanism. Thus, better pyrolysis process ensues using lower heating rates.

Table 1 Proximate, ultimate and calorific value analyses of the teak wood dusts compare to some other biomass.

\begin{tabular}{|c|c|c|c|c|c|c|c|c|c|c|}
\hline \multicolumn{4}{|c|}{ Proximate (\%) } & \multicolumn{5}{|c|}{ Ultimate (\%) } & \multirow{2}{*}{$\begin{array}{c}\text { HHV (MJ/kg) } \\
\text { HHV }\end{array}$} & \multirow{2}{*}{$\begin{array}{c}\text { Type of } \\
\text { Biomass }\end{array}$} \\
\hline MC & VM & $\mathrm{AC}$ & FC & $\mathbf{C}$ & $\mathbf{H}$ & $\mathbf{N}$ & O & $\mathbf{S}$ & & \\
\hline 7.25 & 79.26 & 1.74 & 11.75 & 47.84 & 6.09 & 0.39 & 45.42 & 0.26 & 18.72 & Teak wood $^{++}$ \\
\hline 7.52 & 81.42 & 2.15 & 8.92 & 47.09 & 6.65 & 0.38 & 43.54 & 0.19 & 18.72 & Melina wood $^{+}$ \\
\hline 8.60 & 95.5 & 0.70 & 3.80 & 49.60 & 6.30 & 0.40 & 43.70 & - & 19.80 & Teak wood* \\
\hline 9.40 & 70.40 & 3.50 & 26.10 & 43.90 & 5.30 & 0.40 & 46.90 & - & 16.59 & Iroko wood** \\
\hline
\end{tabular}

*MC (Moisture content), VM (Volatile matter), AC (Ash content), FC (Fixed carbon content,) C (Carbon), H (Hyrogen), N (Nitrogen), O (Oxygen), S (Sulphur), HHV (Higher heating value (calorific value)), ${ }^{++}$This study, ${ }^{+}$Adeleke et al. [25], *Balogun et al. [26] and **Azeez et al. [28].

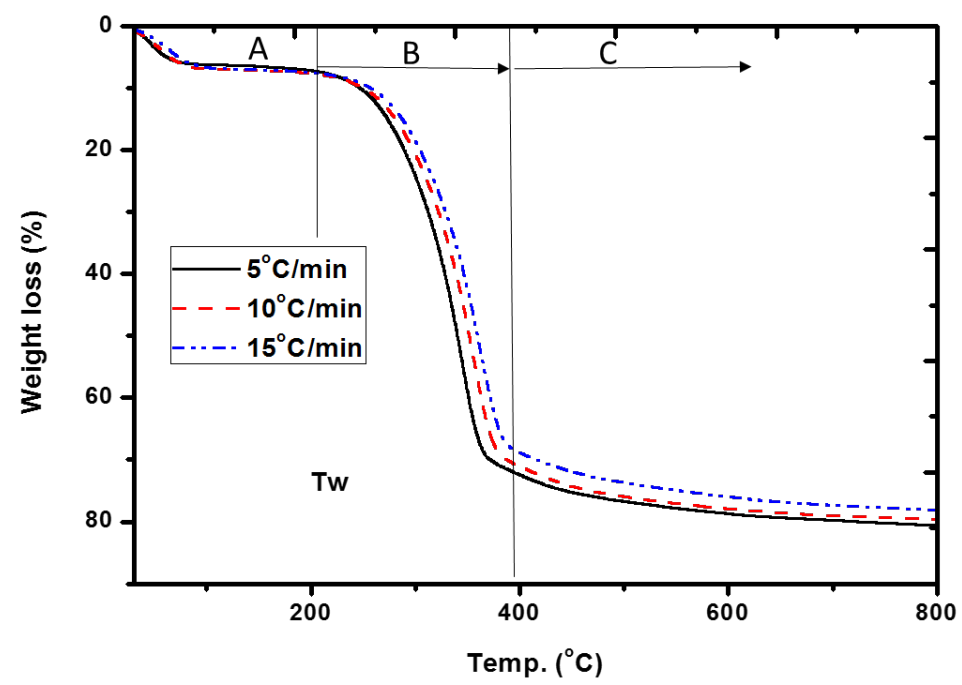

Figure 1 Thermogravimeteric curves for teak wood at different heating rates showing; (A) moisture evolution and reactive drying zone, $(\mathrm{B})$ active pyrolysis zone and $(\mathrm{C})$ passive pyrolysis zone. 


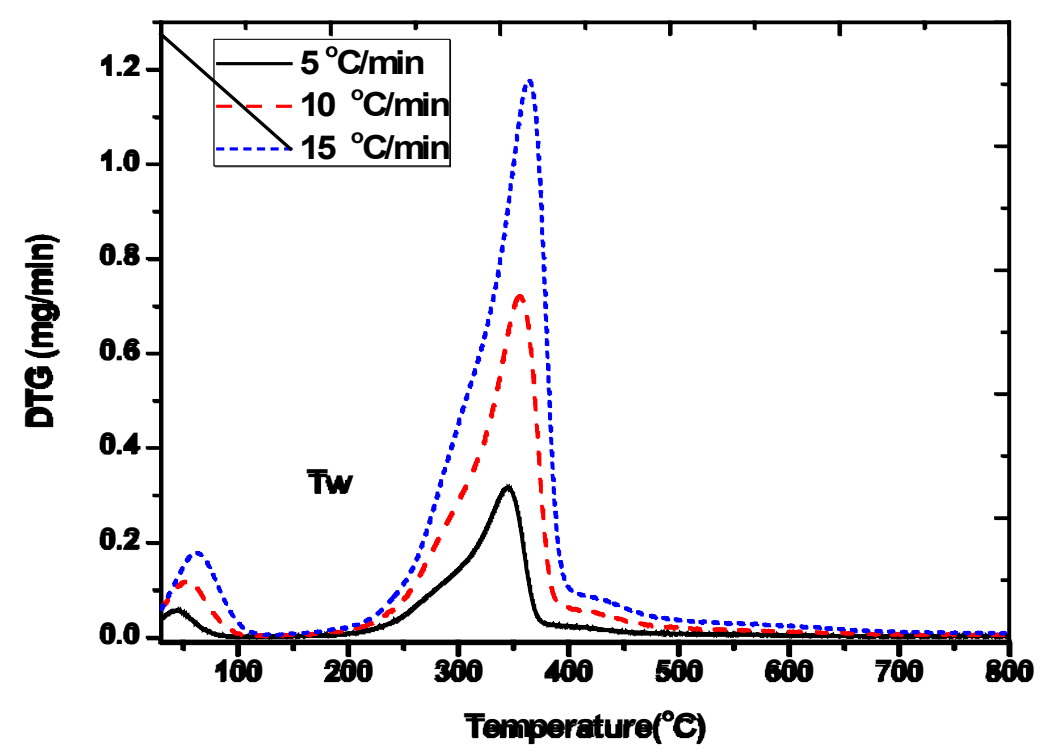

Figure 2 DTG curves for teak wood dust at different heating rates.

\section{Comparison of the models}

The $\alpha$-temperature plot that describes solid-state reactions for teak wood dust is a bell shape which implied that it follows sigmoidal model as shown in Figures 3(a) and 3(b). Skrdla and Robertson [29] suggested that nucleation and nuclei growth models can best describe the acceleratory and deceleratory region of the sigmoidal $\alpha$-temperature curves of which Avrami-Erofeev model is a major type, thus the rationale behind its adoption for the present study. Thermal decomposition of biomass is a heterogeneous reaction and thus Ginstling-Broushtein model [29], a diffusion mechanism was also adopted to fit the heterogeneous solid-state reactions during thermal decomposition of biomass. Figure 4 represents a typical plot of $\ln g(\alpha) / T^{2}$ against $1 / T$ for the active pyrolysis zone (APZ) and Figure 5 represents passive pyrolysis (PPZ) at $5{ }^{\circ} \mathrm{C} / \mathrm{min}$ heating rate for teak wood dust. For the different models employed to fit the thermogravimetric data, negative slopes were obtained for the APZ though with varying correlation factors $\left(\mathrm{R}^{2}\right)$. However, at PPZ, positive slopes were obtained for Avrami-Erofeev and SSS models which implied that negative activation energy values will be interpolated from the linear fit functions. For the 3 heating rates, consistent negative slopes were obtained for APZ (area of major mass loss took place) for the nucleation, diffusion, geometric contraction and reaction order models with relatively high correlation factor $\left(\mathrm{R}^{2}\right)$. However, Ginstling-Broushtein model consistently yield high correlation factor for the 3 heating rates compared to others. The highest correlation factor 0.9993 was obtained with $10{ }^{\circ} \mathrm{C} / \mathrm{min}$ heating rate compared to 0.9802, 0.9905 and 0.9859 of Avrami-Erofeev, SSS and Mampel models, respectively, as shown in Table 3. It implied that diffusion mechanistic assumptions could predominantly explain what take place within the primary pyrolysis zone of the thermal decomposition/degradation of teak wood dust. Khawam and Flanagan [30] explained that in diffusion-controlled reaction, the rate of product formation decreases proportionally with the thickness of product barrier layer. Kinetic parameters obtained via GB model is fitted for adoption during the APZ or the major mass loss arena of teak wood dsut. The GB and Mampel models yielded negative slopes as against the positives slopes of AvramiErofeev and SSS models at different heating rates for PPZ. The positive values obtained for the slopes could be as a result of the inability of the models to capture the overlapping multiple reactions that were taking place simultaneously within this zone [6,31] or simply put that the mechanistic assumptions of these models did not fit for the PPZ. Therefore, GB and Mampel model could be used to obtain the kinetic parameters during the PPZ. However, Mampel model has higher correlation factor $\left(\mathrm{R}^{2}\right)$ than GB at every heating rate as shown in Table 3. The $\mathrm{R}^{2}$ values of $0.991,0.9714$ and 0.9876 for Mampel compared to $0.9787,0.9568$ and 0.9731 of $\mathrm{GB}$ for 5,10 and $15^{\circ} \mathrm{C} / \mathrm{min}$ evidently showed that during the further degradation of cellulose-lignin polymers of teak wood dust (PPZ), Mampel $1^{\text {st }}$ order reaction model is better fit to determine kinetic parameters. Okoroigwe [2] reported that reaction order model adequately correlates the experimental data for thermal decomposition at the passive pyrolysis zone and the stage was referred to as char combustion in his study. The results suggested that prevailing mechanism changes depending on the temperature zone or region of the decomposition process. 
Table 2 Devolatilization parameters based on different heating rates.

\begin{tabular}{lcccccccc}
\hline Sample & $\boldsymbol{\beta}\left({ }^{\circ} \mathbf{C} / \mathbf{m i n}\right)$ & $\begin{array}{c}\mathbf{T}_{\text {onset }} \\
\left({ }^{\circ} \mathrm{C}\right)\end{array}$ & $\begin{array}{c}\mathbf{T}_{\text {peak }} \\
\left({ }^{\circ} \mathrm{C}\right)\end{array}$ & $\begin{array}{c}\mathbf{D T G}_{\text {peak }} \\
(\mathbf{m g} / \mathbf{m i n})\end{array}$ & $\begin{array}{c}\mathbf{T}_{\text {offset }} \\
\left({ }^{\circ} \mathrm{C}\right)\end{array}$ & $\begin{array}{c}\boldsymbol{\alpha}_{\max } \\
(\mathbf{\%})\end{array}$ & $\begin{array}{c}\mathbf{T}_{\text {burnout }} \\
\left({ }^{\circ} \mathrm{C}\right)\end{array}$ & References \\
\hline Teak & 5 & 193 & 321 & 0.3824 & 515 & 50.21 & 602 & This study \\
& 10 & 196 & 330 & 0.5732 & 518 & 48.21 & 606 & This study \\
\multirow{4}{*}{ Melina } & 15 & 198 & 341 & 0.9210 & 524 & 47.46 & 610 & This study \\
& 5 & 191 & 318 & 0.3577 & 444 & 49.96 & 560 & {$[25]$} \\
& 10 & 197 & 326 & 0.4706 & 502 & 49.91 & 607 & {$[25]$} \\
& 15 & 197 & 336 & 0.9194 & 504 & 48.55 & 645 & {$[25]$} \\
\hline
\end{tabular}
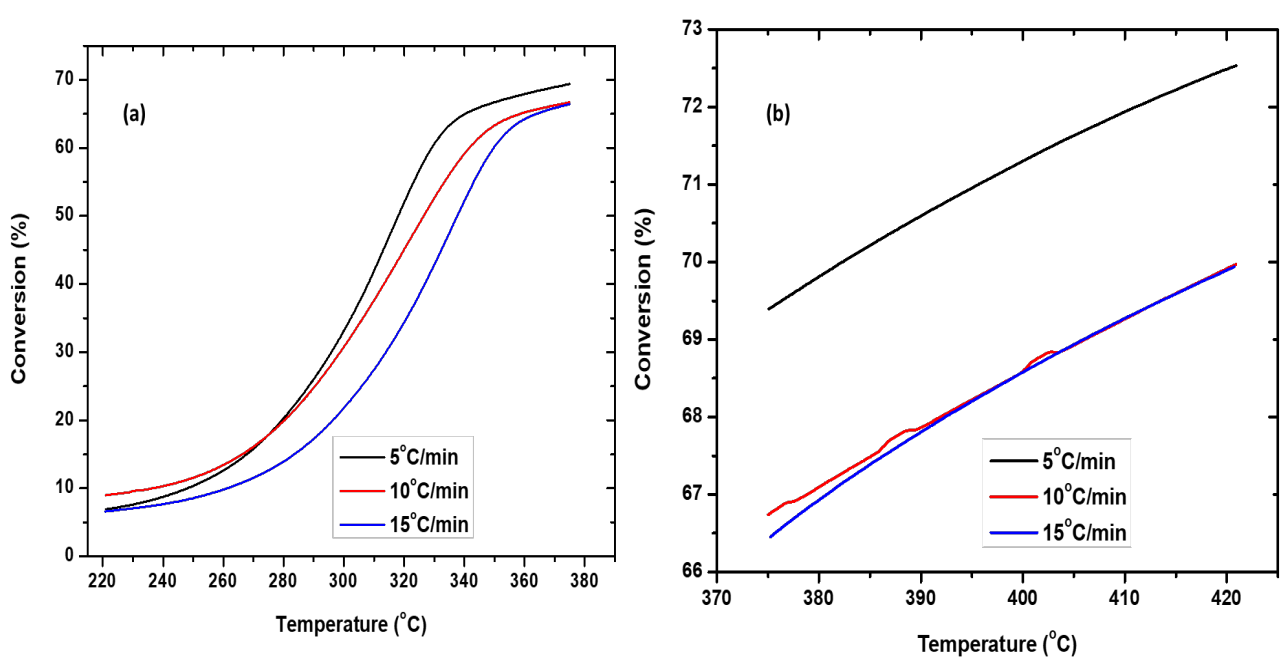

Figure 3 Conversion versus temperature at the different heating rates for (a) active pyrolysis zone (APZ) (b) passive pyrolysis zone (PPZ).

The kinetic parameters of the pyrolysis process of teak wood dust: Activation energy and preexponential factors

The activation energy $\left(E_{a}\right)$ and pre-exponential factors (A) for APZ and PPZ are shown in Figure 6 and Table 3, respectively. The activation energy and pre-exponential factor varies for different models as well as heating rates. This could be as a result of different assumptions upon which each model was developed as previously established. Ginstling-Broushtein is appropriate in reporting the activation energy and pre-exponential factor for APZ as shown in Figure 6 and Table 3. The activation energy is approximately averaged to be $120.45 \mathrm{~kJ} / \mathrm{mol}$ for the 3 heating rates. The activation energy at this stage agrees closely to $125.1 \mathrm{~kJ} / \mathrm{mol}$ that was reported by Okoroigwe [2] for devolatilization kinetics of teak wood dust in a synthetic air environment. Consistent low activation energy values were obtained for all models at passive pyrolysis zone. However, for the high correlation factor $\left(\mathrm{R}^{2}\right)$ of Mampel model, the activation energy at PPZ is $2.67 \mathrm{~kJ} / \mathrm{mol}$. Essentially, the major devolatilization and degradation of teak wood dust polymers took place at the APZ which accounts for the higher activation energy with the 10 $80 \%$ fractional conversion. One advantage of model-fitting method is the ability to capture wide range of fractional conversion at a glance. According to Varhegyi et al. [12], 'a good empirical model should provide a good fit between experimental and calculated data'. The activation energy for PPZ significantly showed that above $80 \%$ conversion, minimum external energy input is required to maintain and further the decomposition and degradation of cellulose and lignin. The pre-exponential factors of approximately $2.0 \mathrm{E}+10 / \mathrm{min}$ showed that the reaction was slow during APZ. Conversely, with A of $7.13 \mathrm{E}-1 / \mathrm{min}$ during PPZ as shown in Table 3, the reaction was swift compared to the APZ. Mortari et al. [32] reported the activation energy of 2 steps thermal decomposition kinetics of bagasse and stated that at passive pyrolysis stage, it was lower compared to the active pyrolysis stage. As discussed earlier, the temperature 
profile (Figure 6) of APZ and PPZ showed that with less external supply of energy, it is possible to obtain maximum devolatilization and conversion into various bio-energy and gases from teak wood dust.

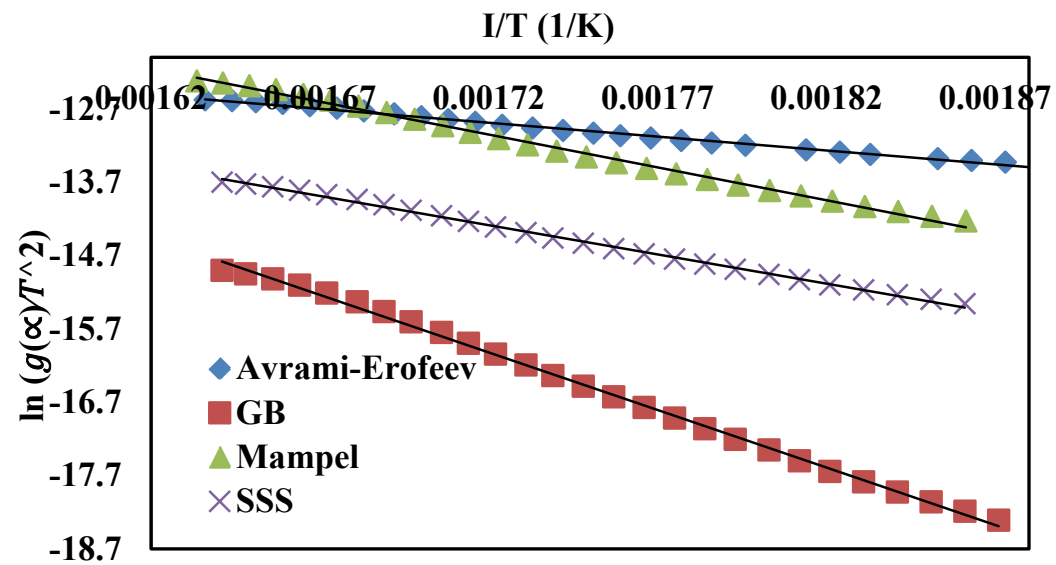

Figure 4 Typical plot for comparing different $\mathrm{g}(\alpha)$ at APZ of teak wood dust at different heating rates (at $5^{\circ} \mathrm{C} / \mathrm{min}$.

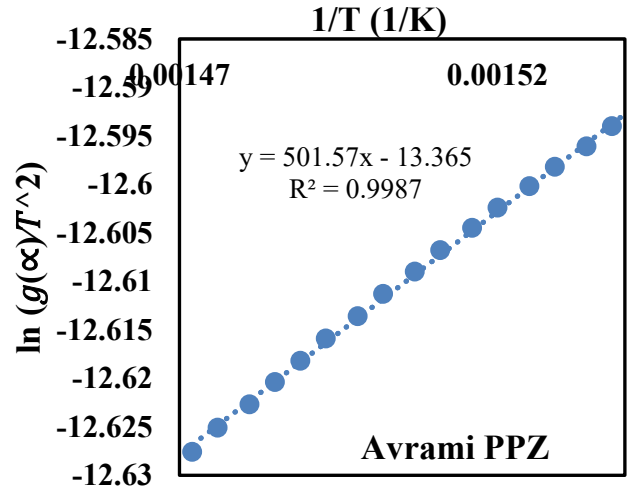

1/T (1/K)

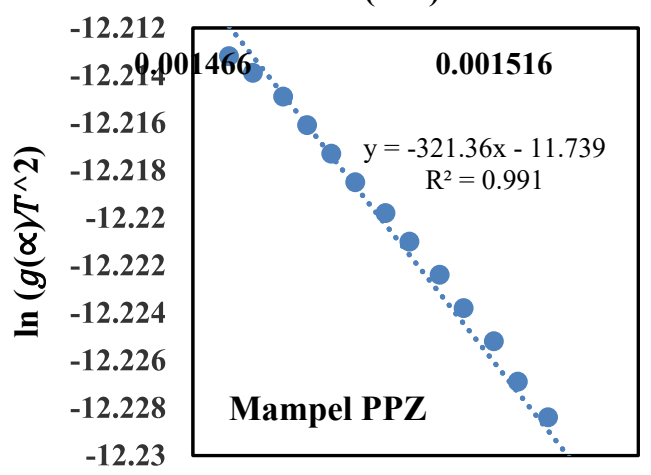

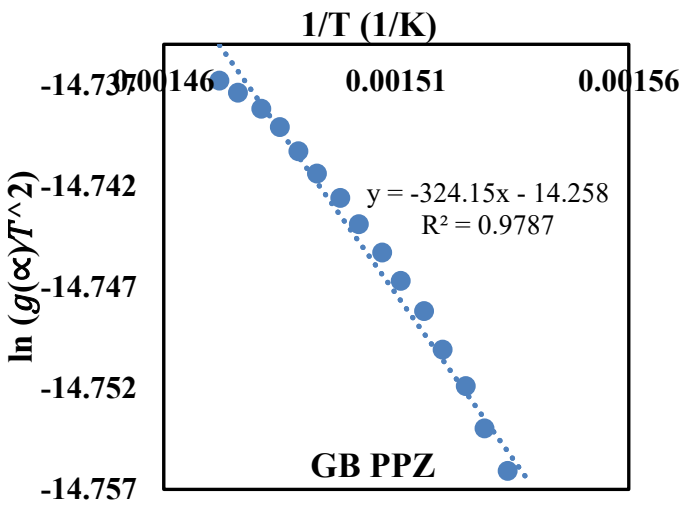

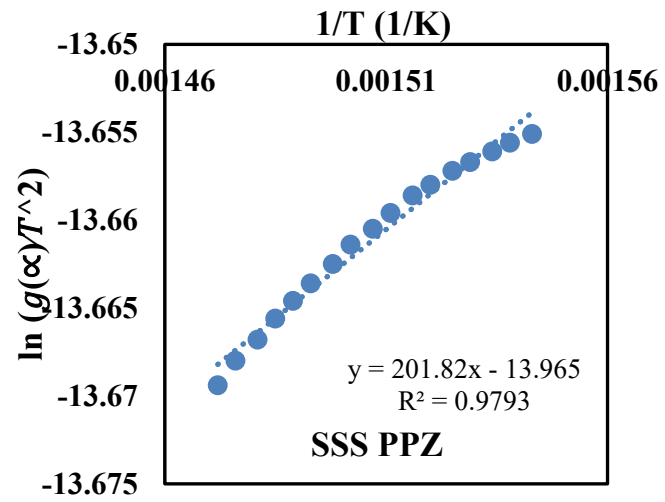

Figure 5 Typical plots for comparing different $\mathrm{g}(\alpha)$ at PPZ of teak wood dust at different heating rates (5 $\left.{ }^{\circ} \mathrm{C} / \mathrm{min}\right)$.

Table 3 Kinetic parameters obtained via the different solid-state reaction models for the 2-pyrolysis zone (active and passive zones). 


\begin{tabular}{|c|c|c|c|c|c|c|c|}
\hline \multirow[b]{3}{*}{$\mathbf{g}(\alpha)$} & & \multicolumn{6}{|c|}{$\beta\left({ }^{\circ} \mathrm{C} / \mathrm{min}\right)$} \\
\hline & & \multicolumn{3}{|c|}{ APZ } & \multicolumn{3}{|c|}{ PPZ } \\
\hline & & 5 & 10 & 15 & 5 & 10 & 15 \\
\hline Avrami- & $E_{a}(\mathrm{~kJ} / \mathrm{mol})$ & 31.97 & 25.15 & 27.98 & -4.17 & -5.06 & -3.71 \\
\hline Erofeev & $\mathbf{A}\left(\min _{\mathbf{R}^{2}}^{-1}\right)$ & $\begin{array}{c}2.11 \mathrm{E}+3 \\
0.9933\end{array}$ & $\begin{array}{c}3.52 \mathrm{E}+2 \\
0.9802\end{array}$ & $\begin{array}{l}6.38 \mathrm{E} 2 \\
0.9703\end{array}$ & $\begin{array}{c}-2.19 \mathrm{E}-1 \\
0.9987\end{array}$ & $\begin{array}{c}-2.23 \mathrm{E}-1 \\
0.9977\end{array}$ & $\begin{array}{c}-2.16 \mathrm{E}-1 \\
0.9926\end{array}$ \\
\hline GB & $\begin{array}{c}E_{a}(\mathrm{~kJ} / \mathbf{m o l}) \\
\mathbf{A}\left(\mathrm{min}^{-1}\right)\end{array}$ & $\begin{array}{c}122.70 \\
2.57 \mathrm{E}+11\end{array}$ & $\begin{array}{c}119.75 \\
1.71 \mathrm{E}+10\end{array}$ & $\begin{array}{c}118.91 \\
1.02 \mathrm{E}+10\end{array}$ & $\begin{array}{c}2.70 \\
5.78 \mathrm{E}-2\end{array}$ & $\begin{array}{c}2.14 \\
3.99 \mathrm{E}-2\end{array}$ & $\begin{array}{c}4.21 \\
1.21 \mathrm{E}-1\end{array}$ \\
\hline SSS & $\begin{array}{c}\mathbf{R}^{2} \\
E_{a}(\mathrm{~kJ} / \mathrm{mol})\end{array}$ & $\begin{array}{c}0.9981 \\
65.57\end{array}$ & $\begin{array}{c}0.9993 \\
53.31\end{array}$ & $\begin{array}{c}0.9893 \\
58.40\end{array}$ & $\begin{array}{l}0.9787 \\
-1.68\end{array}$ & $\begin{array}{l}0.9568 \\
-2.73\end{array}$ & $\begin{array}{c}0.9731 \\
-1.40\end{array}$ \\
\hline & $\mathbf{A}\left(\min ^{2}\right)$ & $\begin{array}{c}1.06 \mathrm{E}+6 \\
0.9971\end{array}$ & $\begin{array}{c}5.71 \mathrm{E}+4 \\
0.9905\end{array}$ & $\begin{array}{c}1.48 \mathrm{E}+5 \\
0.9835\end{array}$ & $\begin{array}{c}-4.83 \mathrm{E}-2 \\
0.97930\end{array}$ & $\begin{array}{c}6.36 \mathrm{E}-2 \\
0.9835\end{array}$ & $\begin{array}{c}-4.33 \mathrm{E}-2 \\
0.9484\end{array}$ \\
\hline Mampel & $\begin{array}{c}E_{a}(\mathrm{~kJ} / \mathbf{m o l}) \\
\mathbf{A}\left(\min ^{-1}\right) \\
\mathbf{R}^{2}\end{array}$ & $\begin{array}{c}74.36 \\
2.13 \mathrm{E}+8 \\
0.9959\end{array}$ & $\begin{array}{c}59.81 \\
8.35 \mathrm{E}+5 \\
0.9859\end{array}$ & $\begin{array}{c}64.03 \\
1.71 \mathrm{E}+6 \\
0.9770\end{array}$ & $\begin{array}{c}2.67 \\
7.13 \mathrm{E}-1 \\
0.9910\end{array}$ & $\begin{array}{c}1.61 \\
3.4 \mathrm{E}-1 \\
0.9714\end{array}$ & $\begin{array}{c}3.97 \\
1.36 \\
0.9876\end{array}$ \\
\hline
\end{tabular}
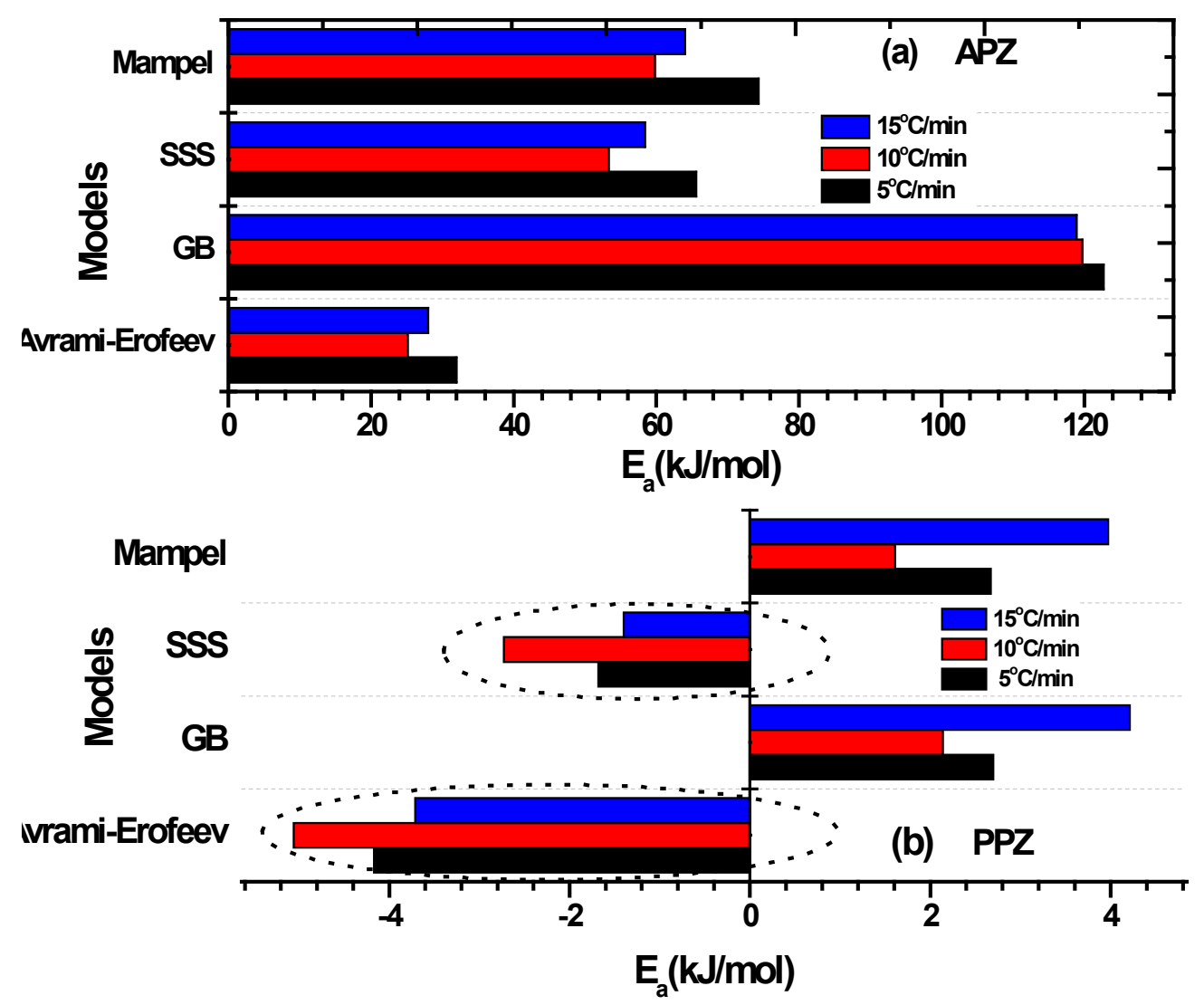

Figure 6 Activation energy obtained via the different solid-state reaction models for (a) active pyrolysis zone (b) passive pyrolysis zones. 


\section{Conclusions}

The evaluation of non-isothermal kinetic parameters for pyrolysis of teak wood using model-fitting techniques was carried out in this study. Teak wood dust contained $7.25 \%$ moisture, $79.26 \% \mathrm{VM}, 1.74$ $\%$ ash and $11.75 \%$ fixed carbon. The calorific value of the teak wood dust was $18.72 \mathrm{MJ} / \mathrm{kg}$. The weight loss of teak wood dust decreased with increase in heating rate. The maximum cellulose decomposition $\left(\mathrm{DTG}_{\text {peak }}\right)$ increased from 0.3824 to $0.9210 \mathrm{mg} / \mathrm{min}$. The maximum conversion $\left(\propto_{\text {max }}\right)$ reduced from $50.21 \%$ at $5{ }^{\circ} \mathrm{C} / \mathrm{min}$ to $47.46 \%$ at $15^{\circ} \mathrm{C} / \mathrm{min}$. The $\alpha$-temperature plot for solid state reaction of teak wood dust was a bell-shape (sigmoidal model). The Avrami-Erofeev and SSS models were unable to capture the overlapping multiple reactions that took place simultaneously at the active pyrolysis zone. Higher energy input is needed for devolatilization of teak wood dust to give $10-80 \%$ conversion due to higher activation energy at the active pyrolysis zone. Reaction rate is low at the active pyrolysis zone but speedy at the passive zone based on the pre-exponential factor. Ginstling-Broushtein was found to be the best model for evaluating the kinetic parameters at the active pyrolysis zone as it had the highest $\mathrm{R}^{2}$ value.

\section{Acknowledgements}

This work was supported by The World Academy of Science (TWAS Award No: FR: 3240287331), Italy and The Council of Scientific and Industrial Research (CSIR FUND: P-81-1-09), India. The authors are also grateful to the Director, CSIR-NML, Jamshedpur, India, for granting us access to their equipment for the research work and permission to publish the research findings.

\section{References}

[1] JK Odusote, AA Adeleke, OA Lasode, M Malathi and D Paswan. Thermal and compositional properties of treated Tectona grandis. Biomass Convers. Biorefinery 2019; 9, 511-9.

[2] E Okoroigwe. Combustion analysis and devolatilazation kinetics of gmelina, mango, neem and tropical almond woods under oxidative condition. Int. J. Renew. Energy Res. 2015; 5, 1024-33.

[3] AA Adeleke, PP Ikubanni, JK Odusote, TA Orhadahwe, OA Lasode, SO Adegoke and OS Adesina. Non-isothermal kinetic parametric evaluation of Tectona grandis using model-fitting methods. Mater. Today Proc. 2021; 44, 2874 -8.

[4] AA Adeleke, JK Odusote, PP Ikubanni, OA Lasode, M Malathi and D Paswan. Essential basics on biomass torrefaction, densification and utilization. Int. J. Energy Res. 2021; 45, 1375-95.

[5] OA Lasode, AO Balogun and AG McDonald. Torrefaction of some nigerian lignocellulosic resources and decomposition kinetics. J. Anal. Appl. Pyrolysis 2014; 109, 47-55.

[6] W Jin, K Singh and J Zondlo. Pyrolysis kinetics of physical components of wood and woodpolymers using isoconversion method. Agriculture 2013; 3, 12-32.

[7] JL Goldfarb and C Liu. Impact of blend ratio on the co-firing of a commercial torrefied biomass and coal via analysis of oxidation kinetics. Bioresour. Technol. 2013; 149, 208-15.

[8] AA Adeleke, JK Odusote, OA Lasode, PP Ikubanni, M Malathi and D Paswan. Mild pyrolytic treatment of Gmelina arborea for optimum energetic yields. Cogent Eng. 2019; 6, 1593073.

[9] A Dhaundiyal and SB Singh. Asymptotic approximations to the non-isothermal distributed activation energy model for biomass pyrolysis. Acta Mech. Autom. 2017; 11, 293-301.

[10] A Soria-verdugo, TM Morgano, H Matzing, E Goos, H Leibold, D Merz, U Riedel and D Stapf. Comparison of wood pyrolysis kinetic data derived from thermogravimetric experiments by modelfitting and model-free methods. Energy Convers. Manag. 2020; 212, 112818.

[11] MP Kothandaraman and M Somasundaram. Non-isothermal kinetic study on copyrolysis of Juliflora and low-density polyethylene. Biomass Convers. Biorefinery 2021; 11, 2147-55.

[12] G Varhegyi, L Wang and O Skreiberg. Non-isothermal kinetics: Best-fitting empirical models instead of model-free methods. J. Therm. Anal. Calorim. 2019; 142, 1043-54.

[13] D Pradhan, GS Mahobia, K Chattopadhyay and V Singh. Effect of surface roughness on corrosion behavior of the superalloy IN718 in simulated marine environment. J. Alloys Compd. 2018; 740, 250-63.

[14] JLF Alves, JCGD Silva, VFDS Filho, RF Alves, WVDA Galdino and RFD Sena. Kinetics and thermodynamics parameters evaluation of pyrolysis of invasive aquatic macrophytes to determine their bioenergy potentials. Biomass Bioenergy 2019; 121, 28-40.

[15] MY Guida, S Lanaya, Z Rbihi and A Hannioui. Thermal degradation behaviors of sawdust wood waste: Pyrolysis kinetic and mechanism. J. Mater. Environ. Sci. 2019; 10, 742-55.

[16] AA Adeleke, JK Odusote, OA Lasode, PP Ikubanni, M Malathi and D Paswan. Densification of 
coal fines and mildly torrefied biomass into composite fuel using different organic binders. Heliyon 2019; 5, e02160.

[17] E Barta-Rajnai, G Varhegyi, L Wang, O Skreiberg and M Gronli and Z Czegeny. Thermal decomposition kinetics of wood and bark and their torrefied products. Energy Fuels 2017; 31, 402434.

[18] RK Chaturvedi and AS Raghubanshi. Allometric models for accurate estimation of aboveground biomass of teak in tropical dry forests of India. Forest Sci. 2015; 61, 938-49.

[19] AA Adeleke, JK Odusote, OA Lasode, D Paswan and M Malathi. Influence of torrefaction on lignocellulosic woody biomass of Nigerian origin. J. Chem. Technol. Metall. 2019; 54, 274-85.

[20] QV Bach, WH Chen, CF Eng, CW Wang, KC Liang and JY Kuo. Pyrolysis characteristics and nonisothermal torrefaction kinetics of industrial solid wastes. Fuel 2019; 251, 118-25.

[21] EAH Castillejos and MFF Tania. Characterization of roughness, porosity and thermal resistances of continuous casting mold slag layers devitrified and crystallized in laboratory. Metall. Mater. Trans. $B$ 2019; 50, 2436-53.

[22] SM Al-Salem, A Bumajdad, AR Khan, BK Sharma, SR Chandrasekaran, FA Al-Turki, FH Jassem, and AT Al-Dhafeeri. Non-isothermal degradation kinetics of virgin linear low density polyethylene (LLDPE) and biodegradable polymer blends. J. Polym. Res. 2018; 25, 111.

[23] JE White, WJ Catallo and BL Legendre. Biomass pyrolysis kinetics: A comparative critical review with relevant agricultural residue case studies. J. Anal. Appl. Pyrolysis 2011; 91, 1-33.

[24] AW Coats and JP Redfern. Kinetic parameters from thermogravimetric data. Nature 1964; 201, 689.

[25] AA Adeleke, JK Odusote, OA Lasode, PP Ikubanni, M Madhurai and D Paswan. Evaluation of thermal decomposition characteristics and kinetic parameters of melina wood. Biofuels 2019, DOI: 10.1080/17597269.2019.1646541.

[26] AO Balogun, OA Lasode and AG McDonald. Thermo-analytical and physico-chemical characterization of woody and non-woody biomass from an agro-ecological zone in Nigeria. Bioresources 2014; 9, 5099-113.

[27] AD Kamble, VK Saxena, PD Chaven and VA Mendhe. Co-gasification of coal and biomass an emerging clean energy technology: Status and prospects of development in Indian context. Int. J. Mining Sci. Technol. 2019; 29, 171-86.

[28] AM Azeez, D Meier, J Odermatt and T Wilner. Fast pyrolysis of African and European linocellulosic biomasses usin Py-GC/MS and fluidized bed reactor. Energy Fuels 2010; 24, 207885.

[29] PJ Skrdla and RT Robertson. Semi-empirical equations for modeling solid-state kinetics based on a Maxwell-Boltzmann distribution of activation energies: Applications to a polymorphic transformation under crystallization slurry conditions and to the thermal decomposition of $\mathrm{AgMnO}_{4}$ crystals. J. Phys. Chem. B 2005; 109, 10611-19.

[30] A Khawam and DR Flanagan. Solid-state kinetic models: Basics and mathematical fundamentals. $J$. Phys. Chem. B 2006; 110, 17315-28.

[31] NA Liu, W Fan, R Dobashi and L Huang. Kinetic modeling of thermal decomposition of natural cellulosic materials in air atmosphere. J. Anal. Appl. Pyrolysis 2002; 63, 303-25.

[32] DA Mortari, I Avila, AMD Santos and PM Crnkovic. Study of thermal decomposition and ignition temperature of bagasse, coal and their blends. Therm. Eng. 2010; 9, 81-8. 